\title{
Calcium phosphate stabilization of fly ash with chloride extraction
}

\author{
Ange Nzihou ${ }^{\mathrm{a}, *}$, Patrick Sharrock ${ }^{\mathrm{b}}$ \\ a*Centre Energétique-Environnement, Ecole des Mines d'Albi-Carmaux, Campus Jarlard, \\ Route de Teillet 81013 Albi CT cedex 09, France \\ ' Institut Universitaire de Technologie, Université Paul Sabatier-av. Georges \\ Pompidou 81104 Castres, France
}

\begin{abstract}
M unicipal solid waste incinerator by products include fly ash and air pollution control residues. In order to transform these incinerator wastes into reusable mineral species, soluble alkali chlorides must be separated and toxic trace elements must be stabilized in insoluble form. We show that alkali chlorides can be extracted efficiently in an aqueous extraction step combining a calcium phosphate gel precipitation. In such a process, sodium and potassium chlorides are obtained free from calcium salts, and the trace metal ions are immobilized in the calcium phosphate matrix. Moderate calcination of the chemically treated fly ash leads to the formation of cristalline hydroxylapatite. Fly ash spiked with copper ions and treated by this process shows improved stability of metal ions. Leaching tests with water or EDTA reveal a significant drop in metal ion dissolution. Hydroxylapatite may trap toxic metals and also prevent their evaporation during thermal treatments. Incinerator fly ash together with air pollution control residues, treated by the combined chloride extraction and hydroxylapatite formation process may be considered safe to use as a mineral filler in value added products such as road base or cement blocks.
\end{abstract}

\section{Introduction}

The conversion of municipal solid waste (MSW) into energy is an well-accepted concept and the main argument in favor of incineration as a treatment process with useful recycling of combustible refuse [1]. As a corollary, it is usual to consider MSW incinerator (MSWI) bottom ash, fly ash or gas scrubber by-products as ultimate unavoidable residues to be disposed of. Scrap metal is recovered but, worldwide, most MSWI fly ash is landfilled.

Landfill is the most expedient, inexpensive disposal method for MSW; however, groundwater pollution from landfill leachate is of concern, as are gas emissions. Furthermore, any toxic products present in the original waste will remain in unknown uncontrolled form in the landfill. Legislation in France calls for the ban of standard landfilling sites in the year 2002 for usual municipal waste. Only non-recyclable waste, so-called "ultimate waste", will be admitted in specifically authorized, well-

* Corresponding author. Tel.: + 33-5-6349-3222; fax: + 33-5-63493099 .

E-mail address: nzihou@enstimac.fr (A. Nzihou). equipped sites. At the present time MSWI ash is solidified with Portland cement and landfilled. However solidification with Portland cement presents some disadvantages, namely protection against humidity is required to prevent breakdown and leaching of heavy metals [1-3].

Interestingly, much effort has been devoted to develop methods to palliate this problem. In particular, ashes can be heated under reducing atmospheres to produce some metal (principally iron and copper) and mostly slag. Alternatively, ashes may be melted at elevated temperatures in a plasma arc furnace to produce a vitreous solid mass [4]. However, these energy costly processes are not economically feasible and suffer from the presence of chloride ions in MSWI ash, which leads to toxic gaseous by-products during thermal treatment [5].

One of the most economical chemical treatments consists in simply washing MSWI ash with water to separate insoluble minerals from water soluble alkali chloride [2]. Unfortunately, heavy metal chlorides are partly extracted [6,7] simultaneously yielding contaminated salt solutions and mineral particles still containing unimmobilized toxic metals in trace amounts. The use of soluble phosphate as a heavy metal chemical stabilization agent has been reported previously [8]. 
We have examined a calcium phosphate sol-gel treatment process combined with a calcination step and report here on the separation of soluble chlorides from MSWI ash and on the insolubilisation of metal ions in a hydroxylapatite containing matrix. Our effort aims to separate alkali chlorides in the water extract and retain the metal ions in the solid phase. We demonstrate that upon crystallization of hydroxylapatite during moderate thermal treatment, the mineral residues show improved resistance to metal ion leaching. Thus, a combined chemical and thermal process may produce usable alkali chlorides and stable apatite-containing silicoaluminate particles, which may be incorporated in cement products.

\section{Materials and methods}

\subsection{Sample collection}

The fly ash used in this study was taken from the municipal waste incinerator in Toulouse as a homogeneous $10 \mathrm{~kg}$ sample. This facility burns over $450 \mathrm{t}$ of waste daily and produces $15 \mathrm{t}$ of fly ash. The stack scrubber was installed in 1994 and includes a semi-dry lime injection unit.

\subsection{Physical and chemical characterization}

The densities were measured with a Micromeretics Accupyc 1330 gas pycnometer. Specific surface areas were measured with a Micromeretic Asap 2010 instrument. Particle size distribution was determined using a Malvern Mastersizer 2000. A Philips XL30 Scanning Electron Microscope was used with semi quantitative analysis performed with a Link analytical EDX analyzer to determine major and minor elements. A Sieffert XRD diffractometer was used to obtain powder X-ray diffraction patterns for the untreated, water-washed and phosphate treated fly ash and a commercial hydroxylapatite reference sample using filtered $\mathrm{Cu} \mathrm{K}$-alpha radiation.

Atomic absorption measurements were made with a Unicam model 919 spectrophotometer using air-acetylene and multielement discharge lamps for calcium and copper determinations.

\subsection{Experimental procedure}

Water-soluble contents were determined on a laboratory bench scale using $10 \mathrm{~g}$ of ash suspended in distilled water, filtering on a Buchner funnel, and evaporating the stirred solutions in beakers heated on a magnetic hot plate.

The various steps of the calcium phosphate treatment process are illustrated in Fig. 1 [8].

In a typical experiment, $1 \mathrm{~kg}$ of fly ash and 21 of distilled water were introduced in a stirred tank reactor of
101 capacity. $\mathrm{Ca}(\mathrm{OH})_{2}(20 \mathrm{~g})$ and $60 \mathrm{~g}$ of $\mathrm{H}_{3} \mathrm{PO}_{4}$ were added. To homogenize the mixture, the suspension was stirred $30 \mathrm{~min}$ at $20{ }^{\circ} \mathrm{C}$ and then filtered with a Faure filter-press equipped with polypropylene tissue filters. Filter cakes were air-dried in a Jouan oven at $60{ }^{\circ} \mathrm{C}$ and calcined in sintered alumina crucibles under air atmosphere at $900{ }^{\circ} \mathrm{C}$ in a Thermolyne muffle furnace. Heavy metal spiked ashes were made by introducing $10 \mathrm{~g}$ of copper chloride dihydrate into the water-ash suspension [9]. Considering that copper was present only in trace amounts in the original ash, the spiking procedure resulted in a final copper concentration of $0.5 \%$ in the washed ashes.

\subsection{Leaching tests}

Following preliminary experiments which revealed very low copper concentrations extracted from treated ashes by conventional distilled water leaching tests; a more aggressive dissolution test was designed. Experiments were carried out using 1\% EDTA or tartaric acid solutions with a liquid to solid ratio of $200 \mathrm{ml}$ of solution for $10 \mathrm{~g}$ of solids. The suspensions were stirred for half an hour and filtered on Buchner funnels to separate the solid and liquid phases.

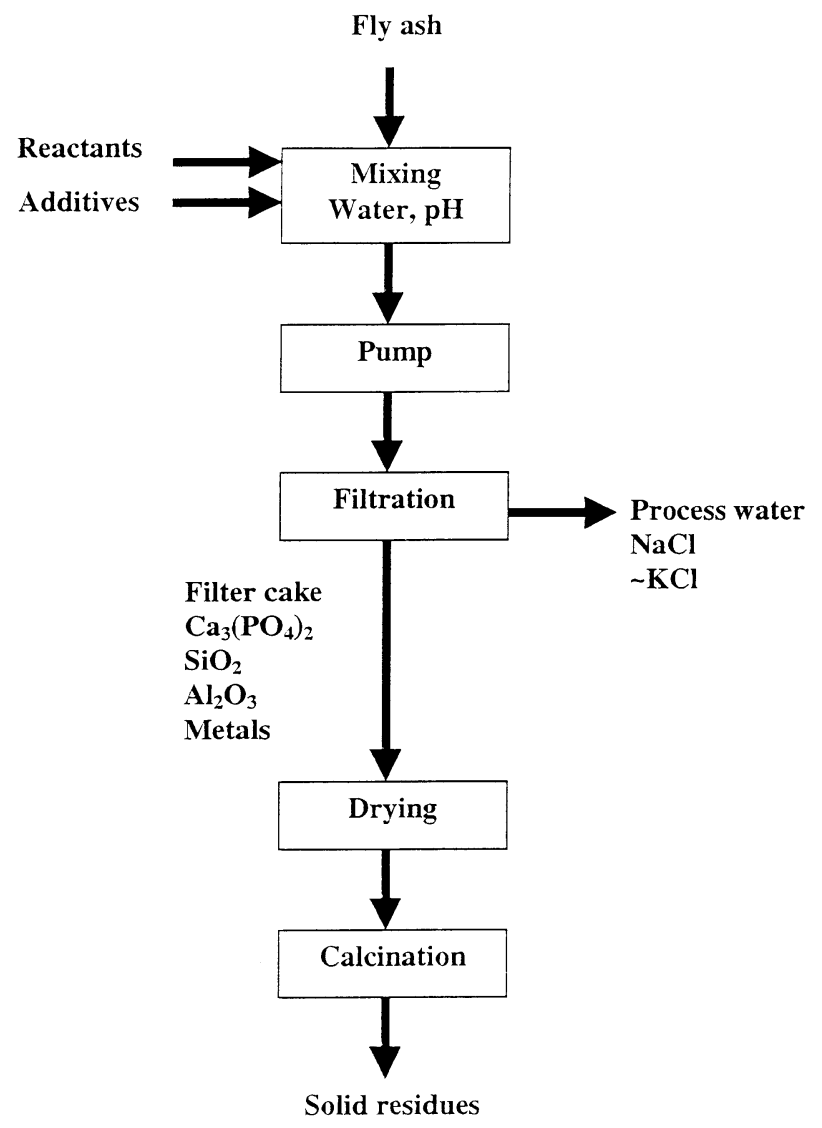

Fig. 1. Experimental set-up. 


\section{Results and discussion}

As usual for MSWI fly ash, the residues are composed of fine particles of heterogeneous composition. Major elements include calcium, aluminum, silicon and chlorine while minor elements include sodium, potassium, sulfur and magnesium. The most abundant trace elements are iron, zinc, copper and titanium. The measured density is $2.63 \mathrm{~g} / \mathrm{cm}^{3}$, close to the average density of light metal oxides. This observed density might be simply related to the average composition of the mostly amorphous particles. The mean particle size is near 5.1 $\mu \mathrm{m}$ when determined in air and $0.49 \mu \mathrm{m}$ when determined in an ethanol. These results reflect the capacity of fly ash particles to agglomerate in air. The specific surface area observed is $4.08 \mathrm{~m}^{2} / \mathrm{g}$.

X-ray diffraction analysis of untreated powders shows many small and ill-defined reflections [10]. However, some mineral species can be identified such as halite, sylvite, anhydrite, quartz, hematite and calcium carbonate. Calcium hydroxide for air pollution control is used near stoichiometric ratio in the MSWI facilities in Toulouse. Washing MSWI fly ash particles with water extracts soluble salts with the efficiency of dissolution, separation and recovery increasing with the amount of water used. The weight $\%$ of extracted salts varies according to the liquid/solid ratios used and reaches a maximal value near $19 \%$. For liquid/solid ratios of 10 , previously used by other authors [7], most of the soluble salts are extracted and only a small fraction (10\%) remains in the solid. Similar results have been reported previously [7]. Evaporation of the solution yields a white crystalline mass composed of halite, sylvite and gypsum. The minerals can be identified by their X-ray powder diffraction pattern and also by thermal analysis as illustrated in Fig. 2. Dehydration of gypsum corresponds to the endothermic weight loss observed near $150{ }^{\circ} \mathrm{C}$, while fusion of sodium chloride and potassium chloride correspond to the minima observed in the heat flow at $801{ }^{\circ} \mathrm{C}$ and $776{ }^{\circ} \mathrm{C}$.

Washed residues, calcined at $900{ }^{\circ} \mathrm{C}$, present weak $\mathrm{X}$ ray diffraction peaks with some modification of the patterns with respect to the untreated MSWI ashes. Sulfates, aluminosilicates, carbonates and oxides are still present, but sylvite and halite are absent. EDX spectra show the same trace elements are visible, present as precipitated hydroxides or included in the mineral matrix. As previously reported, a large fraction of these metals can be leached into solution [3].

When MSWI ash particles are treated with a 10/1 liquid/solid ratio including a calcium phosphate gel formed with a high calcium/phosphorous ratio $(>1.5)$ under basic $\mathrm{pH}$ conditions, the distribution of ions changes. The water extract no longer contains gypsum, and the evaporated solutions contain only halite and sylvite. The washed, treated and dried residues, calcined at $900{ }^{\circ} \mathrm{C}$, show the usual multiple X-ray diffraction patterns of the same mineral species as found previously. Copper phosphate phases, if formed, were not revealed by XRD because of the low total copper

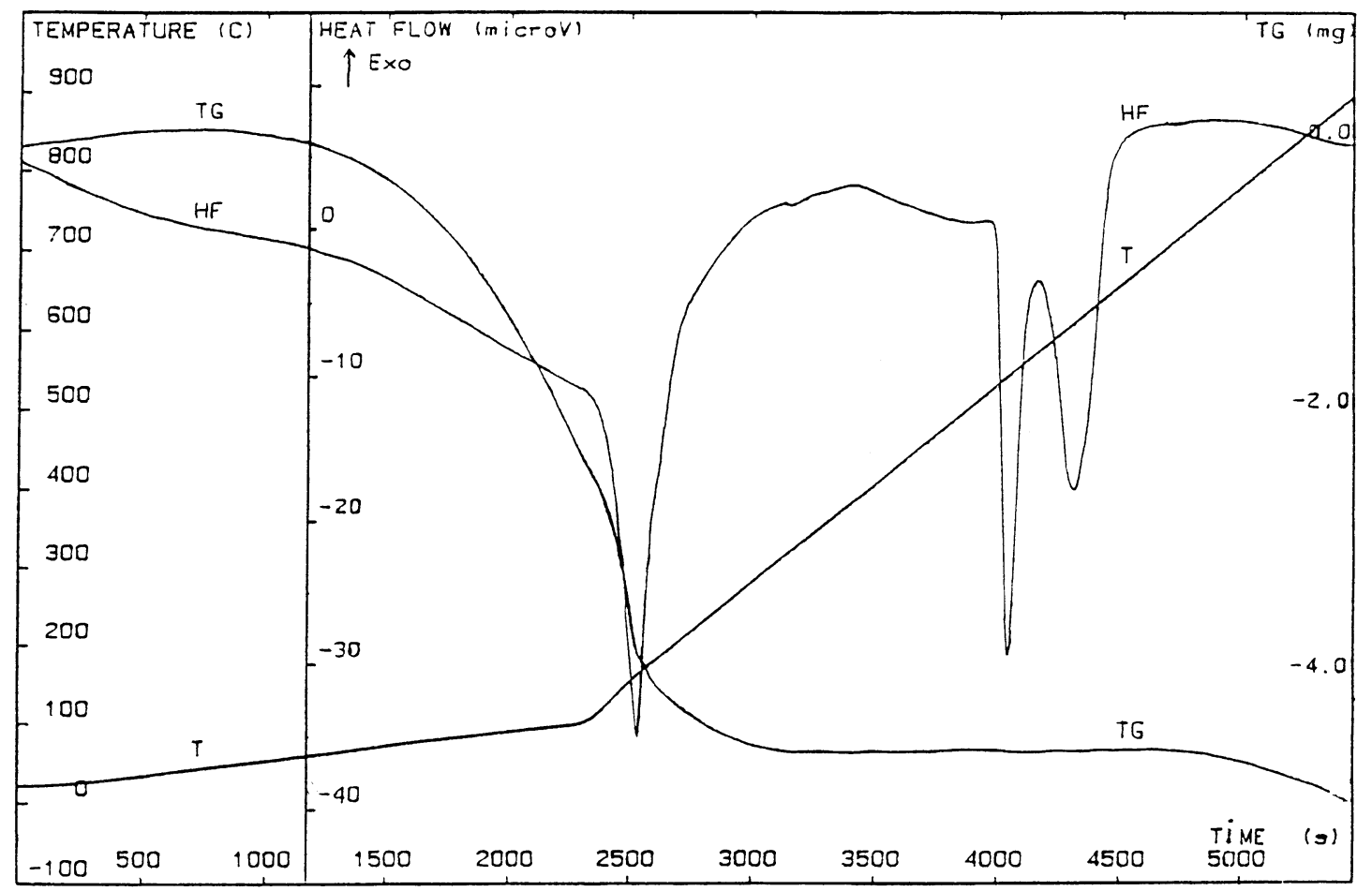

Fig. 2. Thermal analysis of the extracted salt; TG represents the thermogravimetric curve and HF the differential thermal analysis curve. 
concentration and more probable formation of mixed metal phosphates. Closer examination reveals shoulders at the theta angles of $15.875,16.325$ and 12.960 degrees, corresponding to hydroxylapatite peaks. To confirm these assignments, 20 weight $\%$ of powdered hydroxylapatite was added to the treated residues. The resulting X-ray diffraction pattern shows that the corresponding peaks increase in intensity, as illustrated in Fig. 3. Hydroxylapatite is formed during the process according to reaction (1).

$$
\begin{gathered}
10 \mathrm{Ca}_{(\mathrm{aq})}^{2+}+6 \mathrm{H}_{3} \mathrm{PO}_{4(\mathrm{aq})}+2 \mathrm{OH}_{(\mathrm{aq})}- \\
\rightarrow \mathrm{Ca}_{10}\left(\mathrm{PO}_{4}\right)_{6}(\mathrm{OH})_{2(\mathrm{~s})}
\end{gathered}
$$

By isomorphic substitution [11,12], metal ions (copper for example) may be incorporated in the solid matrix according to reaction (2):

$$
\begin{aligned}
& \mathrm{Ca}_{10}\left(\mathrm{PO}_{4}\right)_{6}(\mathrm{OH})_{2(\mathrm{~s})}+\mathrm{xCu}_{(\mathrm{aq})}^{2+} \\
& \rightarrow \mathrm{Ca}_{(1-\mathrm{x})} \mathrm{Cu}_{\mathrm{x}}\left(\mathrm{PO}_{4}\right)_{6}(\mathrm{OH})_{2(\mathrm{~s})}+\mathrm{xCa}_{(\mathrm{aq})}^{2+}
\end{aligned}
$$

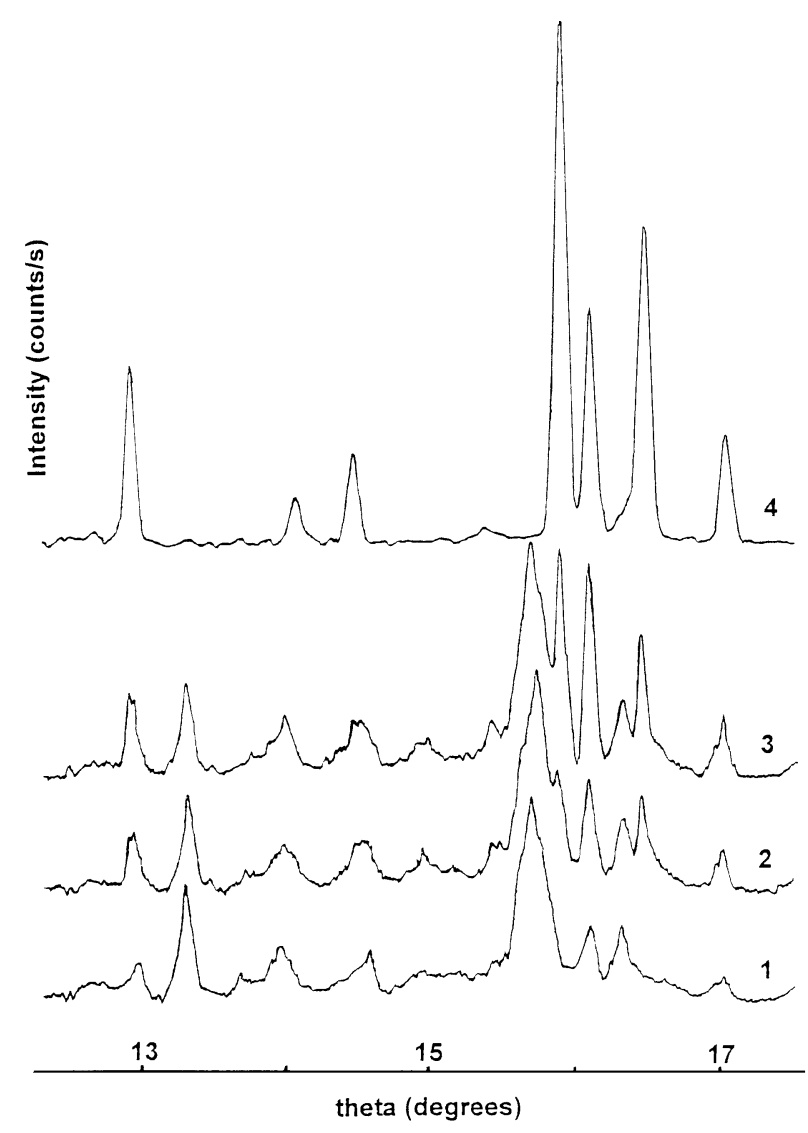

Fig. 3. Powder X-ray diffraction patterns of ash samples. 1: water washed. 2: calcium phosphate treated. 3: calcium phosphate treated with $20 \%$ added hydroxylapatite. 4 : pure hydroxylapatite reference.
MSWI fly ash may contain large amounts of watersoluble salts, most notably sodium and potassium chlorides. Chlorides may be extracted from the ashes in a chemical treatment combining aqueous dissolution and calcium phosphate gel formation. In such a case, the $\mathrm{pH}$ may be adjusted and the calcium/phosphorous ratio adapted to 1.7 , to obtain hydroxylapatite as the end product. This is a special case of phosphate formation, which involves less soluble calcium minerals. The basic $\mathrm{pH}$ prevents formation of more soluble hydrogenophosphate containing minerals. Previous work has centred on soluble phosphate and lime treatment of residues [8] to produce insoluble heavy metal phosphates, such as lead, cadmium or zinc hydroxypyromorphites, $\mathrm{M}_{5}\left(\mathrm{PO}_{4}\right)_{3} \mathrm{OH}$. Other mixed metal hydroxyphosphate compounds likely to be formed include hinsdalite, $\mathrm{PbAl}_{3}\left(\mathrm{PO}_{4}\right)_{3}(\mathrm{OH})_{5} \cdot \mathrm{H}_{2} \mathrm{O}$, and zinc rockbridgeite, $\mathrm{ZnFe}\left(\mathrm{PO}_{4}\right)_{3} \mathrm{OH}$ Typical insoluble mixed metal phosphates are neutral or basic and include tertiary phosphate $\mathrm{Cu}, \mathrm{Ca}_{2}\left(\mathrm{PO}_{4}\right)_{3}$ and apatite $\mathrm{Pb}, \mathrm{Ca}_{4}$ $\left(\mathrm{PO}_{4}\right)_{3} \mathrm{OH}$ family minerals. The very small solubility products of many phosphate minerals make them extremely effective at immobilizing heavy metals in ash. The added interest in hydroxylapatite formation stems from its buffering capacity, its stability and its potential to form insoluble structures with divalent and trivalent metal cations substituting for calcium. It is also convenient to eliminate alkali chlorides from ash residues to facilitate recycling opportunities. The wet chloride extraction combined with the calcium phosphate gel precipitation ensures agglomeration of dust particles. The residues have good handling properties and may be calcined at moderate temperatures without loss of volatile metal chlorides. The effect of calcination on heavy metal dissolution by aqueous ligands was investigated. A significant decrease in copper leachability [9] was observed (Table 1). This effect is related to the incorporation of metal ions in a more compact, crystalline and insoluble calcium phosphate matrix. Substitution of calcium for metal ions accounts for decreased solubility of heavy metals in the apatitic structures [13]. In addition, the good leaching behaviour of untreated and calcined ashes indicates some copper may be incorporated into glassy phases.

Table 1

Effect of calcination on \% copper extracted by EDTA

\begin{tabular}{lc}
\hline Tested residue & $\begin{array}{c}\% \text { Metal } \\
\text { leached }\end{array}$ \\
\hline Untreated fly ash solid residue at $20{ }^{\circ} \mathrm{C}$ & 41 \\
Treated fly ash at $20{ }^{\circ} \mathrm{C}$ & 20 \\
Untreated fly ash calcined at $900{ }^{\circ} \mathrm{C}$ & 2.0 \\
Treated fly ash calcined at $900{ }^{\circ} \mathrm{C}$ & 0.1
\end{tabular}




\section{Conclusion}

Under special conditions, chlorides can be extracted from MSWI ash by water to produce aqueous solutions, which may be evaporated to produce practically pure salts. Calcium phosphates can be formed as a gel to agglomerate fine particles and stabilize the ash by forming insoluble hydroxylapatite. This leads to stable residues with physical characteristics that may be adapted to facilitate beneficial end use [14].

Toxic trace metal ions are trapped in the hydroxylapatite matrix and are less available for aqueous leaching, thus decreasing the hazardous characteristics of the ash [15]. Hydroxylapatite is thermally stable making it possible to harden ash agglomerates by calcination without generating volatile metal chlorides or oxides.

Chemical treatment such as calcium phosphate gel formation effectively reduces heavy metal ion solubilities, particularly under aggressive chelating conditions. Thermal treatment also significantly affects the solubilities of metal ions with respect to chelating ligands. The thermal treatments under mild conditions $\left(900{ }^{\circ} \mathrm{C}\right)$ avoid excessive metal loss by evaporation as metal chloride, but contribute to apatite crystallization, as confirmed by SEM and X-ray diffraction analysis. Chemical and thermal treatments need to be optimized by controlling such parameters as particle sizes, temperature and duration of calcination and nature and quantities of additives. Solving MSWI ash toxicity problems opens new avenues for incineration as the first step in a $100 \%$ recycling process for waste treatment. Combustion will convert organic trash to energy and leave behind inorganic matter. Scrap metal can be mechanically removed from bottom ash. Combined ashes can be washed with water to separate alkali chlorides and chemically treated with calcium phosphate gels to make stabilized mineral species good for value added products. Under proper conditions of operation, incineration is a clean process. It may be the only elimination plan for MSW, which has the capacity to completely recycle all components in an economical way.

\section{References}

[1] Tsiliyannis CA. Report: Comparison of environmental impacts from solid waste treatment and disposal facilities. Waste Manage Res 1999; 17:231.

[2] Andac M, Glasser FP. The effect of test conditions on the leaching of stabilised MSWI-fly ash in Portland cement. Waste Management 1998;18:309.

[3] Berardi R, Cioffi R, Santoro L. Matrix stability and leaching behaviour in ettringite-based stabilization systems doped with heavy metals. Waste Management 1997;17(8):535.

[4] Publication ADEME, Agence de l'Environnement et de la Mấtrise de l'Energie. Les techniques de stabilization des déchets industriels spéciaux. 1996, 66.

[5] Jakob A, Stucki S, Khun P. Evaporation of heavy metals during the heat treatment of municupal solid waste incinerator fly ash. Environ Sci Technol 1995;29:2429.

[6] Lyons MR. The WES-Phix ash stabilization process. Proceedings of the 17th Biennal Waste Processing Conference ASME 1996: 165.

[7] Derie R. A new way to stabilize fly ash from municipal incinerators. Waste Management 1996;16(8):711.

[8] Eighmy TT, Crannell BS, Cartledge FK, Emery EF, Oblas D, Krzanowski JE, Shaw EL, Francis CA. Heavy metal stabilization in municipal solid waste combustion dry scrubber residues using soluble phosphate. Environ Sci Technol 1997;31:3330.

[9] Iretskaya S, Nzihou A, Zahraoui C, Sharrock P. Metal leaching from fly ash before and after chemical and thermal treatment Fly. Environmental Progress 1999;18(2): 144.

[10] Eighmy TT, Eusden J, Krzanowski J, Domingo D, Stamfli D, Martin J, Erickson P. Comprehensive approach toward understanding element speciation and leaching behaviour in municipal solid waste electrostatic precipitator ash. Environ Sci Technol 1995;29:629.

[11] Takeushi Y, Arai H. Removal coexisting $\mathrm{Pb}^{2+}, \mathrm{Cu}^{2+}$ an $\mathrm{Cd}^{2+}$ ions from water by addition of hydroxyapatite powder. Journal of Chemical Engineering of Japan 1990;23(1):75.

[12] Takeushi Y, Susuki T, Arai H. A study of equilibrium and mass transfer in processes for removal of heavy ions by hydroxylapatite. Journal of Chemical Engineering of Japan 1988;21(1):98.

[13] Suzuki T, Hatsishika T, Miyake M. Synthetic hydroxyapatites as organic cation exchangers. Part 2 J Chem Soc Faraday Trans 1 1982;78:3605

[14] Takayuki S, Masataka H. Behavior of stabilized fly ashes in solid landfills. Waste Management 1996;16(56):545.

[15] Kanedo H. Evaluation of municipal solid waste incinerator fly ash toxicity and the role of cadmium by two aquatic toxicity tests. Waste Management 1996;16:555. 